\title{
Effect of a prevention programme on the incidence of rugby injuries among 15- and 16-year-old schoolboys
}

\author{
H Erasmus (MSc (Biokinetics), PhD) \\ E J Spamer (PhD) \\ School for Continuing Teachers' Education, North-West University, Potchefstroom Campus
}

\begin{abstract}
Objective. The primary aim of this study was to determine the effect of an injury prevention programme on the incidence of rugby injuries (overall, intrinsic and extrinsic injuries) among 15- and 16-year-old schoolboys, over a 2year period. A secondary aim was to identify the percentage of intrinsic rugby injuries associated with a previous injury history.
\end{abstract}

Design. A non-equivalent experimental-control group design with multiple post-tests.

Subjects. A- and B-team rugby players $(N=120)$ from 2 secondary schools in the North West province of South Africa.

Intervention. The injury prevention programme was planned according to the physical, motor, biomechanical and postural status of all players. Players in the experimental group received exercises to improve biomechanical and postural deficits identified, as well as drills to address shortcomings in speed, agility, and explosive power.

Main outcome measures. Rugby injuries were screened and injury data collected through the use of weekly sportsmedicine clinics.

Results. Differences and changes in extrinsic injury incidence in this study could not be attributed to the effect of the prevention programme, and as a result injury trends related to overall injury incidence were inconsistent when the matching experimental and control groups were compared. However, the prevention programme did have a positive effect on the intrinsic injury incidence of both the

\section{CORRESPONDENCE:}

\section{E J Spamer}

School for Continuing Teachers' Education

North-West University: Potchefstroom Campus

Private Bag X6001

Potchefstroom, 2520

Tel: 018-299 1611

Fax: 018-299 4312

E-mail: manie.spamer@nwu.ac.za
15- $(d=1.61)$ and 16-year-old $(d=0.83)$ groups during the study period. During the second season there were no intrinsic injuries of a previous nature among both the experimental groups $(0 \%)$, while in contrast intrinsic injuries of a previous nature still amounted to a significant fraction in both the control groups.

Conclusion. The present intervention programme did not have a practically significant effect on the incidence of overall rugby injuries and extrinsic rugby injuries in 15- and 16-year-old schoolboys over a 2-year period. However, in practice the prevention programme did have a significantly positive effect on the incidence of intrinsic rugby injuries among 15- and 16-year-old schoolboys over a period of 2 years. Timely introduction of this programme during the off-season is advised.

\section{Introduction}

At the beginning of the new millennium professional rugby was confronted by several important challenges, one of the biggest being the increasing incidence rate of rugby injuries. ${ }^{3,12,28}$ The tendency for an unacceptable increase in the rate of injuries is also visible at South African school level. $^{13,24}$

The question has already been asked if the elite senior school player has the anthropometric composition, physical and motor abilities, as well as sport-specific skills demanded by the modern game. ${ }^{6,7,22}$ Most school coaches, advocates of talent development and selectors put a high priority on the above abilities and implement programmes to develop bigger, stronger, faster and more skilful players who can excel at their sport. ${ }^{6,8,23}$ However, these programmes do not place enough emphasis on the prevention ${ }^{15,20,23,30}$ and rehabilitation $^{5,12,16}$ of previous injuries. Consequently, the rate of injuries at senior-school level may continue to increase unless preventive measures - sufficient for the modern game - are adopted.

To date, the authors are unaware of other studies that have evaluated the effectiveness of an injury prevention programme in decreasing the prevalence of high school rugby injuries. Therefore the aim of this study was to determine whether an approved injury prevention programme has an effect on the rugby injuries (overall, intrinsic and extrinsic 
injuries) of 15- and 16-year-old schoolboys. A secondary aim was to identify the percentage of intrinsic rugby injuries associated with a previous injury history in this group.

\section{Methods}

A non-equivalent experimental-control group design with multiple post-tests was used in this study. The subjects ( $N$ $=120$ ) were all schoolboy rugby players from 2 secondary schools in the North West province in 2004. Both schools were involved with the Rugby Institute of the North-West University (NWU) (formerly known as PUK Rugby Institute) and had coaches with a similar background and experience which ensured that the teams selected were coached similarly and according to the technical and fitness guidelines supplied by the NWU Rugby Institute. Players who participated in the experimental injury prevention programme were the 15 - and 16-year-old elite A teams $(N=60)$. The B teams $(N=$ $60)$ acted as controls.

This intervention programme was assigned to a team (cluster), not an individual player, because schools wanted all their A-team players to be part of the prevention programme. Furthermore, although a randomised study of individual players and their training practices often provides more realistic results, this may prove difficult for team sports like rugby, as these sports involve different player positions, each with its own exposure to accident hazards (injury risk) and physical demands. In addition, differences even exist between individuals in the same position; for example two A-team loose forwards with different work rates might not run the same distance during a match. This is complicated even more by the role that chance plays in occurrence of extrinsic injuries. However, by using whole teams as the study population, this study was able to meet the research requirements for players of similar age and physical condition participating in a programme with similar exposure to accident hazards and physical demands.

The testing began once the schools and parents had given their approval. Players were evaluated over a 2-year period. During each of the 2 years there were 3 testing occasions - pre-season, during the mid-season break and at the end of the season - where the (i) biomechanical and postural and (ii) physical and motor status of all players were evaluated. The prevention programme was written and adjusted according to the deficiencies identified in the abovementioned tests.

On the day of testing the players rotated between different testing stations. The testing sequence and rest periods between tests were developed in such a way that no previous test would influence subsequent tests.

In addition, injury information was gathered weekly through the use of sports medicine clinics and questionnaires.

\section{Injury definitions}

For the purposes of the study the following definition by Garraway and MacLeod ${ }^{4}$ was used to define a reportable rugby injury: 'an injury sustained on the field during a competitive match or during training, or during other training activities directly associated with rugby, which prevented the player from playing or training from the time of injury or from the end of the match or training session in which the injury was sustained'. Re-injury was defined as an identical injury sustained at least 1 month after the return to the sports activities. ${ }^{17} \mathrm{~A}$ previous injury was described as a positive history of injury in the 12 months prior to the start of the season. ${ }^{10}$ The injury incidence reported in this study is expressed in terms of injuries/1000 player hours. ${ }^{4}$

Injuries were divided into 2 types, namely intrinsic and extrinsic injuries. Intrinsic injuries were injuries associated with repetitive overuse of the body. ${ }^{21}$ Extrinsic (external trauma) injuries were caused by external forces applied directly to the body by someone or something. ${ }^{21}$ The overall injuries were determined as the sum of the intrinsic and extrinsic injuries.

\section{Sports medicine clinics}

Injuries were screened and injury data collected through the use of free sports medicine clinics.

Clinics were held once a week, either on the Monday after a rugby match or during the rest of the week (usually Wednesdays). Each clinic was staffed by a qualified sports physician (medical practitioner specialising in sports injuries) or physiotherapist, biokineticist (specialist in preventive and rehabilitative exercise) and sport scientist (fitness and conditioning specialist, if available). The functions of the clinics were to diagnose, refer (to the player's doctor, physiotherapist, biokineticist or sport scientist) and manage all players who reported an injury. Information relating to the injuries were extracted from these medical records after the end of each rugby season.

\section{Questionnaires}

Before injured players were screened, they had to complete a current and previous injury and rehabilitation information questionnaire. ${ }^{2,10}$ During the sports medicine clinic the injured player and medical staff completed a relevant injury report form for each injury. ${ }^{2}$ These forms were used to register and categorise all rugby injuries.

\section{Battery of tests}

The tests and protocols used for the purposes of this article were chosen from the literature, and their usefulness had been proved in previous studies. ${ }^{6,8,10,22,31}$ These tests were divided into 2 main groups: a biomechanical and postural, and a physical and motor group.

The biomechanical and postural evaluation used a recent approach that measures a combination of muscle and joint symmetry, dynamic mobility and local stability. ${ }^{10}$ Measurements were chosen from common clinical measures of posture and flexibility that could easily be used in a standard biomechanical and postural screening. The biomechanical and postural assessment protocol ${ }^{2}$ (81 measurements in 
total) evaluated 5 different zones, namely lower limb (knee complex, hip joint, foot), pelvic girdle, spinal column, upper limb (shoulder complex) and neurodynamics.

No warm-up exercises were done before the biomechanical and postural evaluation. For the test protocol subjects were dressed in rugby shorts. All tests were completed indoors. One examiner was used to perform the test procedure and an observer/recorder assisted with measurements. ${ }^{2}$ The recorder also served to verify the accuracy of measurement and measurement sequence. The examiner and observer were properly briefed on each individual test procedure and for consistency the same 2 trained medical personnel were used for all tests. During the study all tests were repeated on the left and right-hand side of the subject's body.

Because players also received exercises to improve their speed, agility and explosive power, the physical and motor tests administered were the following: the $10 \mathrm{~m}$ and $30 \mathrm{~m}$ dash for speed, ${ }^{11}$ the Illinois agility run ${ }^{14}$ and vertical jump ${ }^{14}$ for explosive power.

However, as the aim of this article was to discuss results on rugby injuries, a discussion of the results of the various biomechanical and postural, and physical and motor tests does not fall within its scope. The overall methodology used in each specific test, as well as the test results have been described in the study by Erasmus. ${ }^{2}$

\section{Prevention programmes}

Players were given general prevention programmes to address the specific biomechanical and postural, and physical and motor deficits identified on each testing occasion.

In order to optimise conditioning results and prevent overtraining, the prevention programme had to be structured into different cycles, i.e. it had to be periodised. For the purposes of this study, the annual training period was organised into 7 different phases - each phase immediately following the previous one. The 7 phases were as follows:

1. Pre-season programme (3-week preparation programme starting 3 weeks before the first school game).

2. Start-of-season programme Level 1 (6-week maintenance programme).

3. Start-of-season programme Level 2 (advanced maintenance programme).

4. Mid-season programme (1-week conditioning programme starting 1 week before the end of the mid-season break).

5. Mid-season programme Level 3 (most advanced conditioning programme).

6. Post-season transition programme (3 weeks of active rest, recovery and corrective biomechanical/postural exercise following the last game).

7. Off-season programme (low-key programme followed until the start of the pre-season programme, \pm end of January).

Exercises in the same phase were of similar difficulty and intensity, with a gradual increase in difficulty and intensity during the season. Phases 1 and 4 were programmes with a higher volume but lower intensity than the phases that followed them (aim: to regain some lost condition and prepare for the more difficult levels that follow). Number 7 is a low-volume maintenance programme. Levels 1 - 3 (numbers 2, 3 and 5) are programmes lower in volume than numbers 1 and 4 , but higher in level of difficulty (the difficulty rises progressively from level 1 to level 3 , with the latter being the most difficult of the 3 ).

A detailed discussion of each phase of the prevention programme can be found in the study by Erasmus. ${ }^{2}$

\section{Implementation of exercises}

Descriptions and pictures of all the exercises used in the study are given in the study by Erasmus (totalling \pm 60 pages of exercise pictures plus descriptions). ${ }^{2}$

At the start of each season, the coaches and team captains of the relevant teams were educated on the use of the prescribed exercises by the first author (HE). Each experimental group was then provided with an instructional booklet. The author demonstrated all relevant exercises to the players before the start of each training phase. The author visited teams at least twice a week to monitor exercise technique and supervise exercise sessions. On the remaining 2 or 3 days of the week, training was supervised by the coach and team captain. The players did the relevant exercises on their own on days when there was no official training.

Exercises were incorporated into the warm-up and cool-down periods of normal rugby training. The teams all followed their own warm-up of 15 minutes to produce mild sweating without fatigue. Generally, active movements were used to prepare all the major muscle groups for activity, while more sport-specific warm-up movements were used to concentrate on the muscle groups that were expected to be used in the specific day's rugby training activity. After this 15-minute warm-up session, the prescribed exercises commenced. This continued for 20 minutes. Immediately after training, each coach allowed for a period of active cooldown to provide the body with a period of adjustment from exercise to rest. The length of the cool-down varied from 10 to 20 minutes and included jogging and walking, as well as the remaining preventive exercises.

Certain exercises that required weights or other gymnasium apparatus were completed as a daily home exercise programme (this constituted a small part of the total programme). Subjects could choose to complete these exercises either at home, in the school gymnasium, at the local gymnasium or at the injury rehabilitation centre (biokinetics centre) of their choice. Subjects were asked to report their home exercise compliance by noting the days they performed the complete prescribed exercises on a log and to report their compliance weekly. If subjects performed their exercises on fewer than $70 \%$ of the required days, they were not included in the study. To promote honesty, the subjects were allowed continued guidance in their exercise programmes, even in the case of non-compliance. To control the effect that other 


\begin{tabular}{|c|c|c|c|}
\hline & $\begin{array}{l}\text { Intrinsic incidence } \\
\text { (injuries/1 } 000 \text { player hours) }\end{array}$ & $\begin{array}{l}\text { Extrinsic incidence } \\
\text { (injuries/1 } 000 \text { player hours) }\end{array}$ & $\begin{array}{l}\text { Overall incidence } \\
\text { (injuries/1 } 000 \text { player hours) }\end{array}$ \\
\hline Group & $\begin{array}{l}\text { Total period } \\
\text { Mean } \pm \text { SD }\end{array}$ & $\begin{array}{l}\text { Total period } \\
\text { Mean } \pm \text { SD }\end{array}$ & $\begin{array}{l}\text { Total period } \\
\text { Mean } \pm \text { SD }\end{array}$ \\
\hline $\begin{array}{l}\text { 15-year-old experimental } \\
\text { group }(N=30)\end{array}$ & $0.74 \pm 0.52$ & $3.24 \pm 0.11$ & $3.99 \pm 0.57$ \\
\hline $\begin{array}{l}\text { 15-year-old control } \\
\text { group }(N=30)\end{array}$ & $1.98 \pm 0.77$ & $2.77 \pm 0.30$ & $4.75 \pm 1.03$ \\
\hline Inter-group difference ( $d$-value) & $1.61^{*}$ & $1.56^{*}$ & 0.74 \\
\hline $\begin{array}{l}\text { 16-year-old experimental } \\
\text { group }(N=30)\end{array}$ & $0.14 \pm 0.21$ & $3.02 \pm 1.24$ & $3.17 \pm 1.43$ \\
\hline $\begin{array}{l}\text { 16-year-old control group } \\
(N=30)\end{array}$ & $1.21 \pm 1.29$ & $1.96 \pm 0.23$ & $3.17 \pm 1.48$ \\
\hline Inter-group difference ( $d$-value) & $0.83^{*}$ & $0.85^{*}$ & 0.00 \\
\hline
\end{tabular}

resistance training might have on the effect of the prevention programme, all experimental and control groups of players followed the basic age-specific resistance programme of the NWU Rugby Institute in the gymnasium.

\section{Statistical methods}

Data were analysed using the Statistica-7 program. ${ }^{26}$ Descriptive statistics, and effect sizes (practical significance) were used. ${ }^{1,29}$ The groups in this study were not chosen randomly (non-equivalent groups), therefore the $t$-test could not be used to determine the statistical significance of differences in injury incidences. Therefore, only effect sizes (practical significance of differences) ${ }^{1,27}$ were used to describe the differences that occurred.

\section{Results}

\section{Injury incidence}

Mean injury rates for the different groups are shown in Table I. The mean intrinsic injury incidence experienced by the 15year-old experimental group during the total period (2 years) was 0.74 injuries $/ 1000$ player-hours, which is significantly $(d$ $=1.61$ ) less that the mean value of 1.98 experienced by the 15-year-old control group (Table I). Regarding the 16-yearold players, data during the total period mirrored that of the 15 -years-olds, once more finding a high practically significant $(d=0.83)$ difference.

Considering the extrinsic injury incidence reported during this study (Table I), the results for the 2-year period indicate that both the 15- and 16-year old experimental groups experienced significantly more $(d=1.56$ and $d=0.85)$ extrinsic injuries than the corresponding control groups.

The mean overall injury results for the total period indicate that the 15-year-old experimental group experienced 3.99 injuries/1 000 player-hours, which is lower than the mean value of 4.75 experienced by the 15 -year-old control group. In practice, this difference $(d=0.74)$ is not highly significant. This tendency seen in the 15-year-olds (lower overall injury incidence among the experimental group) was not shared by the 16-year-olds. No difference was found between the overall injury incidence experienced by the two 16-yearold groups during the total period, as both the 16-year-old experimental and the 16-year-old control group experienced 3.17 injuries/1 000 player-hours.

\section{Intrinsic injuries with a previous injury history}

The possible influence of previous injuries (injuries during the previous 12 months) on the intrinsic injury incidence is shown in Table II. Among the 16-year-old experimental group, 100\% of intrinsic injuries during the first season were of a previous nature, compared with $33 \%$ in the corresponding control group. A similar pattern is visible in the 15-year-old groups, during the first season. Thus, during the first season it is clear that the majority of intrinsic injuries experienced by all the experimental and control groups - with the exception of the 16-year-old control group - were of a previous nature.

During the second season a different pattern was evident. It is apparent that among both the experimental groups there were no intrinsic injuries of a previous nature visible $(0 \%)$, while in contrast to this intrinsic injuries of a previous nature still amounted to a significant fraction in both the control groups.

\section{Discussion}

\section{Injury incidence}

Firstly, it must be noted that A-team players are normally expected to sustain more overall injuries than players in the lower teams. ${ }^{20,24}$ Likewise, players in the A teams are at increased risk of sustaining intrinsic injuries, as a result of fac- 
TABLE II. Percentage of intrinsic injuries recorded as previous injuries in the experimental and control groups of rugby players during each season

Intrinsic injuries with previous history (as \% of total number of intrinsic injuries)

\begin{tabular}{lll} 
Group & Season 1 & Season 2 \\
\hline $\begin{array}{l}\text { 15-year-old } \\
\text { experimental group }\end{array}$ & 80 & 0 (No intrinsic injuries) \\
$\begin{array}{l}\text { 15-year-old control group } \\
\begin{array}{l}16 \text {-year-old experimental } \\
\text { group }\end{array}\end{array}$ & 60 & 40 \\
$\begin{array}{l}\text { 16-year-old control group } \\
\text { 16 }\end{array}$ & 33 & 0 (No intrinsic injuries) \\
\end{tabular}

tors such as increased pressure to perform at A-team level, as well as the fact that matches are more demanding. ${ }^{9,19,21}$ Similarly, because of the increased intensity with which the game is played at A-team level, these players are at greater risk of sustaining extrinsic (related to trauma) injuries than players in the $B$ teams. ${ }^{21,23}$ However, in the present study the experimental groups (A teams) were the teams receiving the intervention and were therefore expected to experience a reduction in overall injury incidence.

It was expected that the prevention programme would reduce intrinsic injuries (related to overuse) among the experimental groups, as these injuries are related to factors such as poor biomechanics and overuse, which can be prevented. $^{18,21}$ The results of this study show that in practice the 15-and 16-year-old groups which had the injury prevention programme had significantly fewer intrinsic injuries than the corresponding control groups. The success of the prevention programme in reducing intrinsic injury incidence is most likely due to the positive effect of the prevention programme on the biomechanical and postural variables ${ }^{2}$ of the experimental groups.

The fact that the extrinsic injury incidence experienced by both the 15- and 16-year-old experimental groups in this study remained significantly more than that of the corresponding control group illustrates the inability of the prevention programme to reduce the extrinsic injury incidence experienced by the experimental groups to below that of the control groups. This may be attributed to the fact that the prevention programme was not designed to reduce extrinsic injury incidence, ${ }^{2}$ as there are too many unpredictable elements (associated with contact situations) present in the occurrence of these injuries. ${ }^{21}$

This study showed that the prevention programme did not reduce the overall injuries of the 15- and 16-year-old experimental group to significantly below the injury incidence in the corresponding control groups. This may be explained by the fact that factors such as aging, ${ }^{15,21}$ level of play ${ }^{20,21,24,25}$ and pressure to perform ${ }^{19}$ may have led to inconsistencies in extrinsic injury incidence. In turn these changes in extrinsic injury incidence during the 2 years may be responsible for the incoherent pattern detected in the overall injury incidence, seeing that overall injury incidence consists of the sum of the intrinsic and extrinsic injury incidence.

\section{Intrinsic injuries with a previous injury history}

The percentage of intrinsic injuries with a chronic nature are shown in Table II. These results signify that during the first season of intervention, intrinsic injuries of a previous nature remained a dilemma, even in the presence of the prevention programme. This could suggest that these injuries were not fully rehabilitated before the start of the study, or that the causes of these injuries were not removed completely during the first season of the study.

During the second season a different pattern emerged. It is evident that among both the experimental groups there were no intrinsic injuries of a previous nature visible $(0 \%)$, while in contrast to this intrinsic injuries of a previous nature still amounted to a significant fraction in both the control groups. This could have been due to the rehabilitative effect of the prevention programme, as this programme is specifically aimed at reducing biomechanical shortcomings in the experimental groups. Therefore it can be concluded that during the second season the prevention programme possibly had a more significant effect on shortcomings due to previous injuries. To the best of the authors' knowledge this finding has not been investigated by previous studies. This pattern during the second season suggests that the programme restored certain impaired functions, and therefore had more of a rehabilitative than a preventive effect during the first season. Because of this certain deficiencies were overcome, and the programme could reach its preventive potential during the second year.

\section{Conclusions}

The prevention programme used in this study had a positive effect on the intrinsic injury incidence of 15- and 16-yearold schoolboy rugby players, particularly during the second year of study after the programme had been implemented for 1 year. Therefore this prevention programme can serve as a model for the reduction of future intrinsic rugby injury incidence among 15- and 16-year-old schoolboys, as well as a basis for further study on the prevention of rugby injuries among senior schoolboys.

\section{References}

1. Ellis SM, Steyn HS. Practical significance (effect sizes) versus or in combination with statistical significance (p-values). Management Dynamics 2003; 12: 51-3.

2. Erasmus $\mathrm{H}$. The effect of a prevention programme on the rugby injuries of 15- and 16-year old schoolboys. PhD thesis, Potchefstroom University, 2006.

3. Garraway WM, Lee AJ, Hutton SJ, Russell EB, MacLeod DA. Impact of professionalism on injuries in Rugby Union. Br J Sports Med 2000; 34: 348-51.

4. Garraway M, MacLeod D. Epidemiology of rugby football injuries. Lancet 1995; 345: 1485-7.

5. Gerrard DF, Waller AE, Bird YN. The New Zealand rugby injury and performance project, II: previous injury experience of a rugby-playing cohort. Br J Sports Med 1994; 28: 229-33. 
6. Hanekom AJ. Anthropometriese, fisieke, motoriese en vaardigheidseienskappe van senior sekondêre skoolrugbyspelers in die Noordwesprovinsie. MA thesis, Potchefstroom University, 2000.

7. Hare E. Die identifisering van rugbytalent by seuns in die senior sekondêre skoolfase. MEd thesis, Potchefstroom University, 1997.

8. Hare E. Longitudinale studie van talentvolle jeugrugbyspelers met verwysing na vaardigheid, groei en ontwikkeling. PhD thesis, Potchefstroom University, 1999

9. Harvey JS. Overuse syndromes in young athletes. Clin Sports Med 1983 2: $595-607$

10. Hattingh JHB. A prevention programme for rugby injuries based on an analysis among adolescent players. PhD thesis, Potchefstroom University, 2003.

11. Hazeldiner R, McNab T. The RFU Guide to Fitness for Rugby. London: A \& C Black, 1998

12. Holtzhausen LJ. The epidemiology of injuries in professional rugby union in South Africa. MPhil thesis, University of Cape Town, 2001.

13. Jakoet I. Contrast injuries in schoolboy rugby. South African Sports Medicine Association Congress, Johannesburg, 2002

14. Kirby RF. Kirby's Guide to Fitness and Motor Performance Tests. Cape Girardeau: Ben Oak Publishing Company, 1991.

15. Lee AJ, Garraway WM. Epidemiological comparison of injuries in school and senior club rugby. Br J Sports Med 1996; 30: 213-7.

16. Lee AJ, Garraway WM, Arneil DW. Influence of preseason training, fitness, and existing injury on subsequent rugby injury. Br J Sports Med 2001; 35 $412-7$

17. Lynsens RJ, De Weerdt W, Niewboer A. Factors associated with injury proneness. Sports Med 1991; 12: 281-9.

18. McGinnis PM. Biomechanics of Sport and Exercise. 2nd ed. Champaign, III: Human Kinetics Publishers, 2005.

19. Micheli LJ. Overuse injuries in children's sports: The growth factor. Orthop Clin North Am 1983; 14: 337-60.
20. Nathan M, Goedeker R, Noakes TD. The incidence and nature of rugby injuries experienced at one school during the 1982 rugby season. S Afr Med J 1983; 64: 132-7.

21. Noakes TD, Du Plessis M. Rugby Without Risk: A Practical Guide for the Prevention and Treatment of Rugby Injuries. Pretoria: JL van Schaik, 1996.

22. Plotz AF. 'n Vergelykende studie van Suid-Afrikaanse en Engelse adolessente eliterugbyspelers met verwysing na spelspesifieke, antropometriese en fisiek-motoriese veranderlikes. MEd thesis, Potchefstroom University, 2004.

23. Quarrie KL, Handcock P, Toomey MJ, Waller AE. The New Zealand rugby injury and performance project. IV. Anthropometric and physical performance comparisons between positional categories of senior A rugby players. Br J Sport Med 1996; 30(1): 53-5.

24. Roux CE. The epidemiology of schoolboy rugby injuries. MSc thesis, University of Cape Town, 1992

25. Roux CE, Goedeke R, Visser GR, Van ZyI WA, Noekes TD. The epidemiology of schoolboy rugby injuries. S Afr Med J 1987; 71: 307-13.

26. Statsoft Inc. Statistica. Data analysis software system, Version 7, 2005, www.statsoft.com.

27. Steyn HS jun.. Practical significance of the difference in means. Journal of Industrial Psychology 2000; 26(3): 1-3.

28. Targett SG. Injuries in professional rugby union. Clin J Sport Med 1998; 8: $280-5$.

29. Thomas JR, Nelson JK. Research Methods in Physical Activity. 4th ed. Champaign, III.: Human Kinetics, 2001.

30. Upton PA, Roux CE, Noakes TD. Inadequate pre-season preparation of schoolboy rugby players. A survey of players at 25 Cape Province high schools. S Afr Med J 1996; 86: 531-3.

31. Van Gent MM. A test battery for the determination of positional requirements in adolescent rugby players. PhD thesis, Potchefstroom University, 2003

\section{CURRENT Diagnosis \& Treatment: Sports Medicine Author: Patrick J McMahon \\ August 9, 2006; Paperback; 624 pages 0071410635 / 9780071410632}

\section{Readable. Comprehensive. Up-to-date. The one book to have for day-to-day answers in sports medicine.}

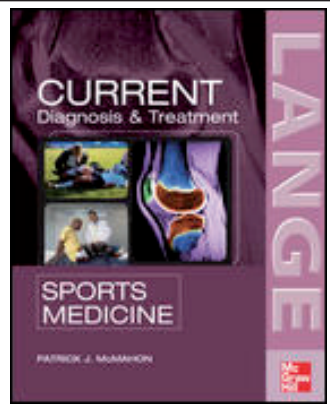

- Authoritative, point-of-care coverage with evaluation, treatment, and management of all common sports injuries

- Essential evidence-based stabilization and rehabilitation techniques

- Prevention strategies featured throughout

- Pre-participation and on-the-field evaluation

- Practical guidance on sports injuries in children

- Coverage of the medical issues of female athletes

- In-depth treatment of concussion

- Up-to-date information on medical conditions and sports participation

- Numerous easy-to-read diagnostic charts, tables, and treatment graphs

- Concise, current, and comprehensive review of the biomechanics of sports medicine

- Helpful references to classic and important new sources

- Online updates at companion site CURRENTMED.COM 